\title{
Study on the Planning Strategies of Urban Street Open Space Constrained by the Environment in Winter City
}

\author{
Zhiqing Zhao", * Liu Cong ${ }^{2}$, Jiajun $\mathrm{Hu}^{3}$, Yanyan $\mathrm{Zhao}^{4}$ \\ ${ }^{1}$ College of Architecture Key Laboratory of Urban and Rural Human Settlements Science in Cold Region of Heilongjiang, Harbin Institute of \\ Technology, Harbin, China \\ ${ }^{2}$ College of Architecture, Harbin Institute of Technology, Harbin, China \\ ${ }^{3}$ College of Architecture, Xi'an University of Architecture and Technology, Xi'an, China \\ ${ }^{4}$ Urban Planning and Design Institute of Harbin Institute of Technology, Harbin, China
}

\section{Email address:}

Zhaozq88@hit.edu.cn (Zhiqing Zhao),1652408489@qq.com (Liu Cong),jiajun_0@sina.com (Jiajun Hu), 1154987956@qq.com (Yanyan Zhao)

${ }^{*}$ Corresponding author

\section{To cite this article:}

Zhiqing Zhao, Liu Cong, Jiajun Hu, Yanyan Zhao. Study on the Planning Strategies of Urban Street Open Space Constrained by the Environment in Winter City. Science Discovery. Vol. 5, No. 7, 2017, pp. 554-560. doi: 10.11648/j.sd.20170507.24

Received: November 14, 2017; Accepted: November 23, 2017; Published: December 28, 2017

\begin{abstract}
Street open space, as a necessary place for residents to conduct interpersonal interaction in the city, serves as an important space for people to exchange material, energy and information with nature. In Harbin, a winter city, Dasongbei area, as a newly built zone, leads the strategic forefront in promoting new urbanization, whose open space has drawn increasing attention in its environmental construction. This paper summarizes four planning modes of street open space and some existing problems through field investigation and interview for Dasongbei area, such as inadequate consideration on citizen demands, neglect of weather factors in winter cities, monotonous plant landscape, etc. Under regional environment context, combining with the influence of the cold climatic elements on the street open space construction, this paper puts forward suitable and sustainable planning strategies of street open space so as to guide the planning and design of street open space in other winter cities.
\end{abstract}

Keywords: Winter Cities, Street Open Space, Climate, Planning Strategies

\section{寒地环境约束下城市街头开放空间规划策略研究}

赵志庆 ${ }^{*}$, 刘聪 ${ }^{2}$, 胡家骏 ${ }^{3}$, 赵研妍 ${ }^{4}$

${ }^{1}$ 建筑学院, 黑龙江省寒地城乡人居环境科学重点实验室, 哈尔滨工业大学, 哈尔滨市, 中国

2建筑学院, 哈尔滨工业大学, 哈尔滨市, 中国

建筑学院, 西安建筑科技大学, 西安市, 中国

4哈尔滨工业大学城市规划设计研究院, 哈尔滨市, 中国

邮箱

Zhaozq88@hit.edu.cn（赵志庆）, 1652408489@qq.com（刘聪）,jiajun_0@sina.com（胡家骏）, 1154987956@qq.com（赵研妍）

摘要: 街头开放空间是城市中居民进行公共交往的必要性场所, 也是人们与自然进行物质、能量和信息交流的重要空 间。作为寒地城市的开发建设新区, 哈尔滨市大松北地区是推进新型城镇化的战略前沿, 其街头开放空间的环境建设 日益受到关注。本文通过实地踏查、访问等方式归纳出大松北地区街头开放空间的四种规划模式, 总结出其存在的一 些问题, 如对寒地气候因素及市民需求考虑不足、植物造景方式单调等。结合寒地气候要素对于街头开放空间建设的 
影响, 在地域性环境背景下提出适宜的、可持续的街头开放空间的规划策略, 以期对其它寒地街头开放空间的规划设 计起到一定的指导作用。

关键词: 寒地城市, 街头开放空间, 气候, 规划策略

\section{1. 引言}

随着大规模的城市化建设和城市空间的快速增长， 中国各城市在空间建设方面取得了相当大的成就。但由 于过快的城市发展和过度的重视空间数量增长而忽视空 间质量提高，使得目前的城市空间中出现了种种问题。 其中作为承载社会生活, 体现城市政治、经济、文化特 征、构成城市物质环境的街头开放空间建设问题不容小 视, 在此基础上, 寒地街头开放空间的建设在大松北地 区更成为了人们关注的焦点, 如冰雪天气所导致的路滑、 街头开放空间缺少气候防护设计或防护设施、休闲设施 材质使用不当等, 在极大程度上限制了人们的外出活动, 从而影响到空间的使用效率和频率。因此如何在寒地街 头开放空间的规划中突出季节转换、寒地特色、差异规 划成为设计重点和难点。

因此本文基于研究对象的地域性限制, 以大松北地区 九处街头开放空间为例, 通过实地调研总结目前寒地街头 开放空间存在的主要问题, 并将问题从科学的、理性的、 人本的角度进行分类解析, 从而提出寒地环境约束下街头 开放空间的规划设计策略, 力求达到改善寒地城市街头开 放空间品质、突出城市特色, 创建宜居的、生态的、人文 的空间环境的目的。

\section{2. 街头开放空间的项目概况与解析}

\section{1. 街头开放空间的项目概况}

寒地城市（winter cities）是根据城市所在地域的冬 季气候特征所定义的一个比较笼统的概念, 具有气温一 般在 $0^{\circ} \mathrm{C}$ 以下、通常以雪的形式降水、日照或白昼时间短 暂、季节变化明显等特征, 通常意义上涵盖中国东北全 部地区, 华北全部地区以及西北的部分地区。根据区域 统筹的要求, 哈尔滨提出 “大松北”的概念。依据《哈尔 滨市城市总体规划（2011-2020）》和《哈尔滨松北发展 战略》, 大松北地区研究范围是指松花江北岸的松北、 呼兰两个行政区, 面积 2933 平方公里, 占市辖区的 $28.7 \%$, 占全市的 $5.5 \%$ 。规划范围为城市总体规划中心城区规划 范围内的江北地区, 主要对松北区、呼兰区、利民开发 区和松花江避暑城等地区进行统筹规划, 总用地面积 1357平方公里。

街头开放空间通常是指道路红线以外、沿街布置面积 不大的开放性公共空间。其主要功能是装饰街景, 美化城 市, 提高城市环境质量, 同时为游人及附近居民提供游悡、 交流、娱乐场所。具有公共性、多样性、时代性的特征, 同时具有数量多且分布较广的特点, 是提高城市绿化品质 以及改善居民生活质量的有效手段。
项目位于哈尔滨市的大松北地区, 通过实地调研发现 其主要的街头开放空间仅有九处, 主要分布在前进片区中 源大道、松北大道、江湾路、国道1001所在的区域环境内 以及呼兰片区南京路上。

表1 大松北地区主要街头开放空间现状统计表。

\begin{tabular}{llll}
\hline \multirow{2}{*}{ 名称 } & \multicolumn{3}{l}{ 街头开放空间特征 } \\
\cline { 2 - 4 } & 面积 $\left(\mathrm{m}^{2}\right)$ & 性质 & 所属区域 \\
\hline 哈尔滨科技创新新城广场 & 10845 & 街头广场 & 前进片区 \\
哈尔滨市政府北部街头绿地 & 73600 & 街头绿地 & 前进片区 \\
润福公园 & 45500 & 街头绿地 & 前进片区 \\
江湾路天元街交界处街头绿地 & 58300 & 街头绿地 & 前进片区 \\
江湾路松北大道交界处街头绿地 & 18200 & 街头绿地 & 前进片区 \\
湖滨小镇前街头绿地 & 3500 & 街头绿地 & 前进片区 \\
广厦学院前街头广场 & 3200 & 街头广场 & 利民片区 \\
呼兰区政府南侧街头绿地 & 39000 & 街头绿地 & 呼兰片区 \\
南京路与利民东一大街交界街头 & 7850 & 街头绿地 & 呼兰片区 \\
绿地 & & & \\
\hline
\end{tabular}

大松北地区做了多版包括战略规划、总体规划、绿地 系统等专项规划在内的多层次的且具有指导城市建设意 义的规划, 然而在具体的建设管理过程中按照新区的大尺 度建设机制, 缺乏以人为本的思想, 往往忽略与居民生活 息息相关的街头开放空间的营造，居民（尤其老人）对于 建立设施相对完整、管理相对完善、满足一定服务半径的 街头开放空间的诉求强烈, 也是大松北地区建设人性化的 居住环境迫切需要解决的问题。

总体来说，大松北地区现有的街头开放空间数量不 足, 分布不均匀, 对于大松北地区覆盖程度有所欠缺, 这些问题反映出了大松北地区城市广场在布局上缺少整 体性思考和系统性规划及对于人们的需求有所忽略。

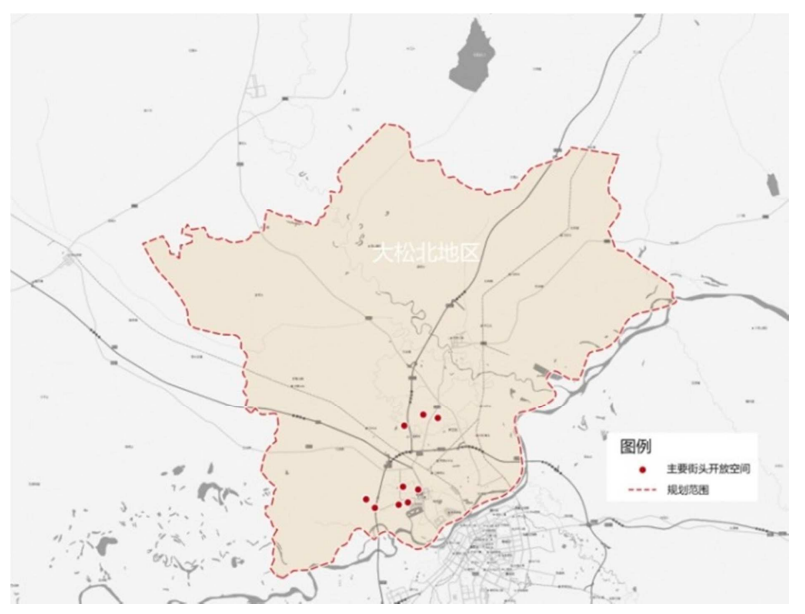

图1 大松北地区主要街头开放空间分布图。 


\section{2. 街头开放空间的项目解析}

城市街头开放空间的形态是特定的城市经济、技术、 社会和政治状况的综合反映, 是在错综复杂的背景因素影 响下, 经过了漫长又复杂的生长和演变过程形成的。地理 位置和自然条件使城市禀赋了某种与生俱来的特征, 合理 并巧妙的利用不但可以突出城市特色, 也可以维护城市的 自然景观, 美化城市形象。在对大松北地区实地调研基础 上，依据开放空间场地的围合环境，探讨出大松北地区街 头开放空间有如下四种组合关系:

\subsection{1. 模式一: 街头开放空间=居住区 + 大学校园 + 城市道 路}

模式一在大松北地区街头开放空间中是较为常见的 一种。研究范围内湖滨小镇前街头绿地和广厦学院前街头 广场均属于此模式（如图2）。南邻城市道路, 北靠大学 校园南门, 东西两侧均为居住小区, 虽然规模不大却是周 边居民活动的主要场所，同时也是学生驻足停留、路过的 主要空间, 学生群体活动具有钟摆效应, 在中午或傍晚时 会达到人流集聚的高峰。

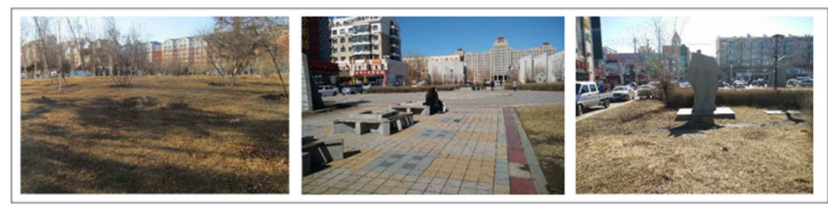

图2 模式一街头开放空间现状图。

\subsection{2. 模式二: 街头开放空间=居住区 + 其他开敞空间 + 城市道路}

模式二在大松北地区开放空间中有两处，分别为呼 兰区政府南侧街头绿地和哈尔滨市政府北部街头绿地 （如图3）。整体空间结构与模式一类似，北侧的功能区 为其他开敞空间, 南邻城市道路, 东西均为居住区, 对 于此类空间由于临近地块为行政办公性质，所以在空间 使用上以市民和办公人员居多，但由于周边用地性质的 影响使空间在规划上呈现了大、空、旷的特点, 尤其开 放空间北侧是相似性质的用地，进一步加剧了这种空间 感受。
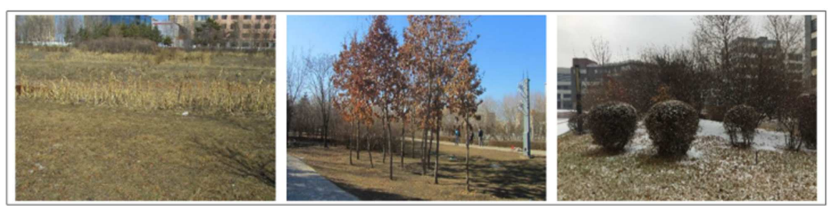

图3 模式二街头开放空间现状图。

\subsection{3. 模式三: 街头开放空间=居住区+城市道路}

模式三在大松北地区开放空间中有三处, 分别为润福 公园、江湾路天元街交界处街头绿地、江湾路松北大道交 界处街头绿地（如图4）。开放空间的东、北两侧为居住 区, 西、南两侧紧邻城市道路, 景观特征较为明显, 开放 程度较高, 有良好的步行视觉体验。区域内按人群活动不 同大致分为三类：居住建筑附近绿地集中了游款、休息、
聊天等活动; 邻路一侧主要以步行者形式为主, 但步行人 数不多; 核心广场区则集中了大量人群, 并在春夏秋人数 较多, 其中夏季游园人数最多, 冬季由于气候原因, 人数 极少。

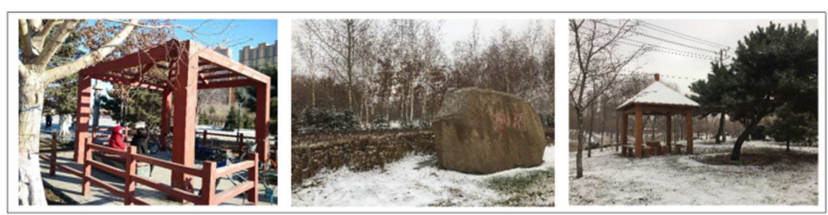

图4 模式三街头开放空间现状图。

\subsection{4. 模式四：街头开放空间=办公区+城市道路}

模式四在大松北地区开放空间中有一处，为哈尔滨科 技创新新城广场（如图5）。开放空间东西两侧紧邻城市 道路, 南北为办公区, 虽然拥有优越的地理位置, 但由于 城市道路的分割使东西向人流大大减少，导致使用空间的 人群具有单一性。同时, 冬季气候的低温、寒风及降雪进 一步减少了开放空间的吸引力, 使空间环境的氛围无比萧 条。

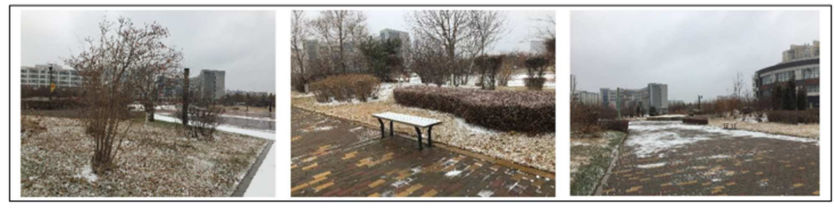

图5 模式四街头开放空间现状图。

\section{3. 寒地城市街头开放空间存在问题}

\section{1. 街头开放空间对寒地气候因素考虑不足}

冬季气候条件恶劣是寒地城市街头开放空间塑造良 好的冬季景观的最大障碍。在寒冷气候环境下，低温、寒 风、日照均是规划街头开放空间需要考虑的要素, 低温会 使植物枯萎、水凝结成冰、景观设施会随着冬季低温而变 得冰冷, 难以使用。对于冬季寒风, 城市发展一般是建筑 已经建设完毕后才轮到城市街头开放空间建设, 周围高层 建筑的分布情况会使空间内部风环境紊乱, 影响场地微环 境的舒适度。而日照对于冬季景观来说更加可贵, 寒地城 市街头开放空间设计多数情况只考虑到了夏季遮阳的需 求, 对冬季摄取日光考虑不周, 甚至有些景观设施被布置 在建筑物的阴面, 且阴影区域也很难开展任何活动, 利用 率很低。

\section{2. 街头开放空间的植物造景方式单调}

在寒地街头开放空间普遍存在对植物配置设计不够 重视的问题，由于地域的限制使植物种类在选择上不同 于南方地区，在设计上不能盲目的生搬硬套南方的设计 理念。在植物配置方面, 大部分设计师在进行植物配置 时仅仅局限于植物的花叶层面，对植物的整体造型、树 枝的形状和色彩等植物冬态美的塑造欠缺思考。对植物 季节变化考虑不周, 缺乏针对冬季而进行的植物配置, 同时配置方式缺乏乔木、灌木和地被植物的配合应用， 
难以形成植物群落和生态循环链, 景观层次较差, 无法 保证在春夏秋有良好景观效果的种植设计在冬季也表现 出同样良好的状态。

\section{3 . 街头开放空间的景观设施没有考虑到市民的需求}

符合人行为心理的环境, 能够激发市民使用街头开 放空间的渴望。美国著名社会心理学家马斯洛在《人类 动机理论》一书中, 提出了满足人需求的层次理论, 即 生理、安全、社交、自尊、自我实现五种需求, 只有在 低层次需求得到满足的前提下高层次需求才能得到满 足。对大松北街头开放空间来说, 常规和寒地特有景观 设施都存在欠缺的问题, 且景观设施材质的选择是设计 成败的关键要素之一, 笔者在调研时发现, 有些广场空 间采用了大理石条登作为休息设施, 虽然在造型上富有 较强的吸引力, 甚至根据人体工程学原理考虑了使用者 的需求, 但在冬季几乎无法被使用, 从本质上来讲就是 以牺牲其使用功能为代价来实现其美学价值。同时, 寒 地空间景观色彩的营造也十分重要, 寒地冬季一般采用 燃煤等燃料的方式进行采暖, 会排放大量的烟雾的同时 干燥的天气使得城市粉尘飞扬令城市蒙上了一层灰色, 另外冬季花草调零、树木枯萎, 使空间景观效果大打折 扣, 缺乏生机与活力。

\section{4. 寒地城市街头开放空间设计策略}

\section{1. 利用气候因素塑造寒地景观}

\section{1. 1. 街头开放空间的选址与布局}

选址是街头开放空间设计的第一步, 应详细考虑地形 地貌、水、风向、植被等相关要素, 因为其直接关系到空 间的建成效果。在空间设计中, 最重要的是要关注场地周 边的环境状况, 尤其是建筑和植被的分布情况对风向和日 照分布的影响, 以便在营造避风向阳的场地时, 将主要的 活动场地布置在建筑物南侧阳光充足的地带。同时, 街头 开放空间的均衡化布局也是创造良好生活环境空间的必 要条件，以满足市民使用空间的可达性要求。

宏观上，以大松北地区各种不同类型的街头开放空间 为基本单元, 确定合理服务半径, 着重分析现有街头开放 空间对区域内居民的服务面积覆盖情况，从而找到研究区 内街头开放空间的服务盲区, 为下一步合理调整街头绿地 布局提供理论依据（其中街头公园的服务半径为 $1000 \mathrm{~m}$, 街旁绿地的服务半径为 $500 \mathrm{~m}$ ）。

微观上, 针对街头开放空间周围不同的用地功能, 采 用不同的建设尺度（如表2）。在商业区内用地紧张、寸 土寸金的情况下，通常建设小尺度的街头开放空间，以满 足路人、游客、周边职员休息的需要为主。中等及较大尺 度的开放空间可以提供丰富的景观, 根据场地情况布置半 开敞式或开敞式空间, 对于地形复杂的地段, 设计时应考 虑因地制宜, 与周边环境的融合。

表2 不同区域的街头开放空间服务特征。

\begin{tabular}{lllll}
\hline \multirow{2}{*}{ 区域类型 } & \multicolumn{3}{l}{ 不同区域的街头开放空间服务特征 } & 功能 \\
\cline { 2 - 5 } & 用地情况 & 尺度 & 主要服务对象 & 休息、停留 \\
\hline 商业区 & 紧张 & 0.1 公顷以下 & 游人、周边职员 & 交往、活动、游䡯 \\
居住区 & 充裕 & $0.5-1.2$ 公顷 & 居民、路人 & 休息、交流 \\
工业区 & 相对充裕 & $0.1-0.5$ 公顷 & 工人、居民 & 交流、放松、解压 \\
文教区 & 相对充裕 & $0.1-0.5$ 公顷 & 学生、教师、居民 & \\
\hline
\end{tabular}

\section{1. 2. 街头开放空间的围合与遮挡}

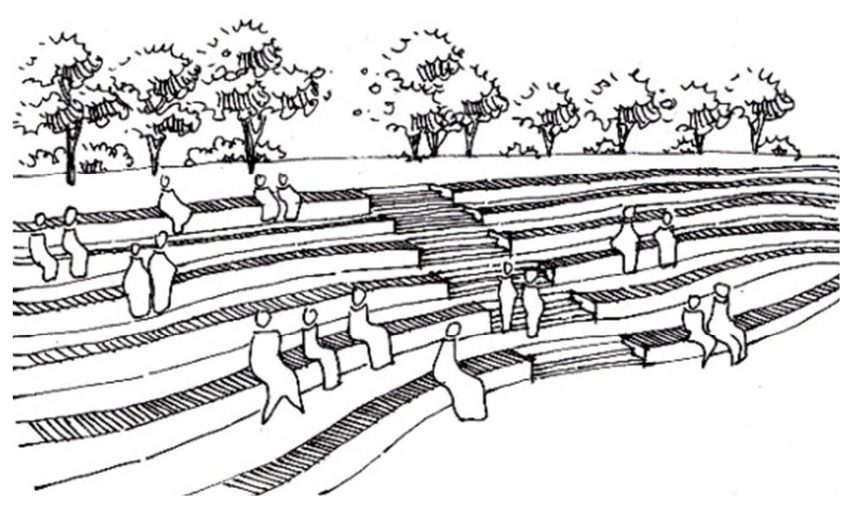

图6 通过微地形设计创造围合空间。

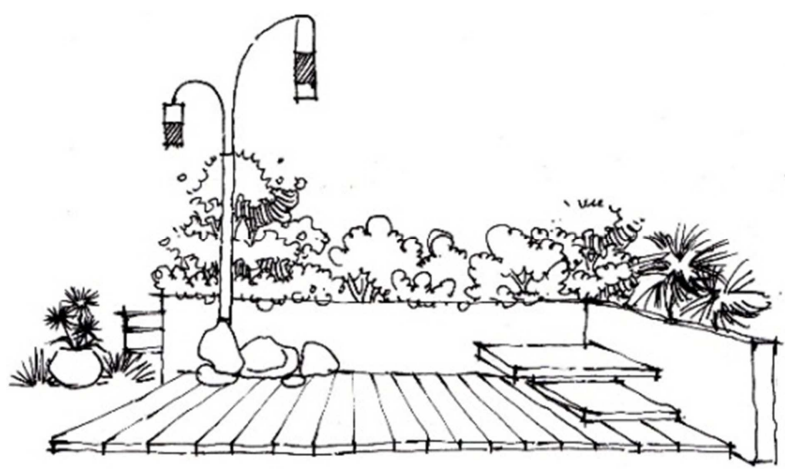

图7 通过挡风墙设计创造围合空间。

在地处寒地的大松北地区营造避风向阳的城市街头 开放空间时，空间围合和对冬季盛行风的遮挡是能否实现 营造良好场地小气候的关键。街头开放空间的围合物包括 地形、建筑物或不通透的构筑物及树木等 (如图6、图7), 只要设计合理, 这些手段均能发挥良好的挡风效应。而大 
松北地区存在的四种模式的街头开放空间各具特点, 其围 合与遮挡方式也各有不同。

（1）模式一（如图8）地块的空间可塑性强，未来发 展空间较大, 但由于北侧大学校园的存在, 空间多为大面 积的硬质铺装以供学生及市民进行交流与活动, 景观特点 较为单一, 可在街头开放空间地形上做一定的围合处理, 在广场西侧或北侧做逐层递减的空间, 增强空间的吸引力 及创新性的同时起到保暖防寒的效果。东西两侧的多层居 住区对空间产生一定的围合作用, 并且住宅底层的商业对 于激发空间活力, 吸引周边市民有着积极意义。

（2）模式二（如图9）的街头开放空间中，由于北侧 其他开敞空间的存在，使得区域内开放空间的面积大幅度 增加, 对市民的吸引力也相应增强, 但南北通透的街头开 放空间要注意对于寒地西北风的气候防护, 可在冬季寒风 的盛行风向即空间西北向设置具有防风效果的乔灌木及 构筑物等来阻挡寒风袭击; 在向阳面配置落叶树种, 以利 于场地在冬季获取日照, 形成避风向阳的适合活动的场地 空间。使具有相同或相似性质的用地接连在一起时, 既能 满足空间设计上的连续性与相互关联性, 又能避免空间环 境的同质化。

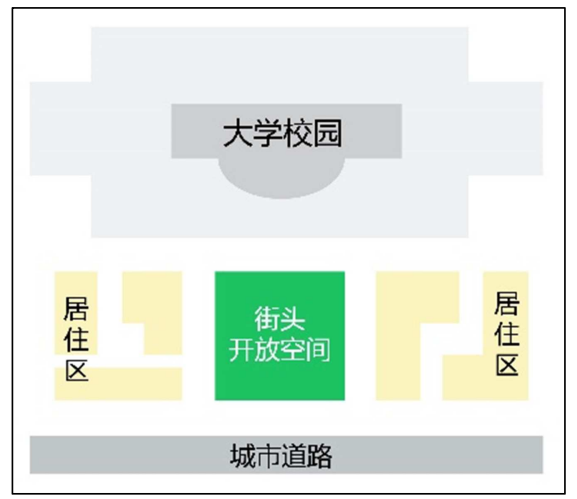

图8 模式一。

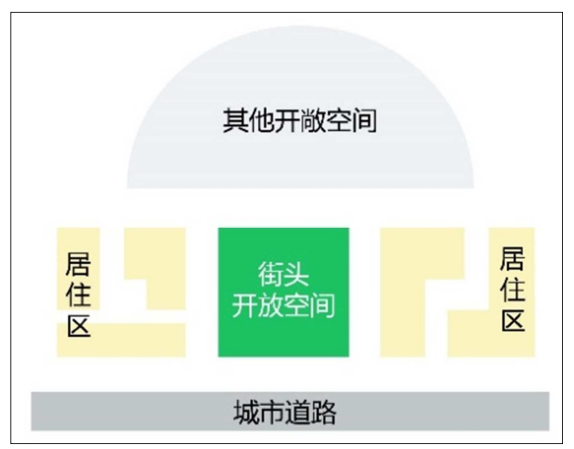

图9 模式二。

（3）模式三 (如图10) 地块的空间有较高的使用率, 笔者调研时发现, 周边居住区的老年使用者居多, 但随着 天气转凉, 开放空间内的活动人数大大减少。首先, 对于 老年人冬季跨路活动难度增加; 其次, 对于空间的防寒考 虑不足, 尤其是针对使用人群的相关防寒设计的缺失, 是 该地块设计的重点。设计方法上，可在地块西侧和南侧设 置适当数量的乔木，使其在遮挡寒风的同时增加空间的可
视性。也可以通过不通透的构筑物如挡风墙、用于挡风的 景观设施创造围合空间, 当构筑物高于 $1.8 \mathrm{~m}$ 时, 形成全封 闭空间; 低于 $0.3 \mathrm{~m}$ 则只能对人的心理造成分割的影响, 并 不能在实际上形成对空间的围合。所以围合空间的营造既 要充分考虑人体的尺度又要考虑影响空间封闭程度的构 筑物的高度, 才能创造出宜人的空间环境。

（4）模式四（如图11）的街头开放空间周边环境较 为良好, 南北两侧均为办公区, 空间使用的人群具有青年 化的特点, 对此为吸引冬季人流在防寒设计方面也提出了 更高的要求。首先, 该街头开放空间可在步行系统与城市 结合、与周边建筑的渗透关系上有所考虑, 在开放空间南 北两侧设置可供人直接通行的景观步道来连接南北办公 区。同时, 周边建筑多以居住和办公功能为主, 对空间有 一定的遮挡作用, 可以在建筑底层提供街头广场的渗透空 间。其次, 空间结构上硬质铺装面积过大, 多为地面层, 设计上可增加对地上层、地下层的考究, 打造寒地冬季室 外活动的友好环境。

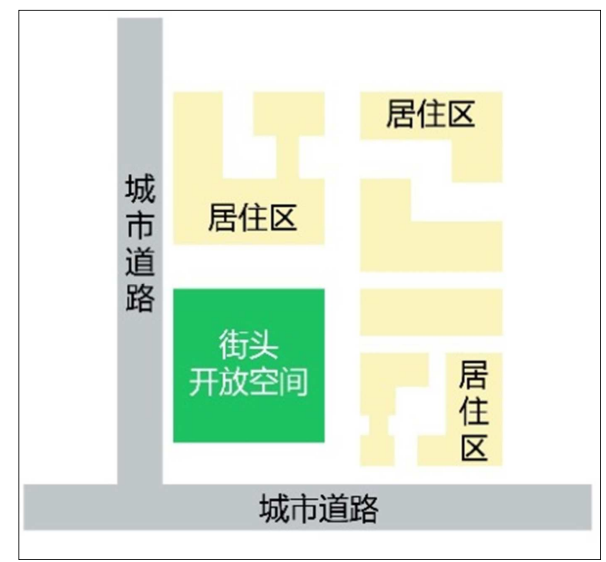

图10 模式三。

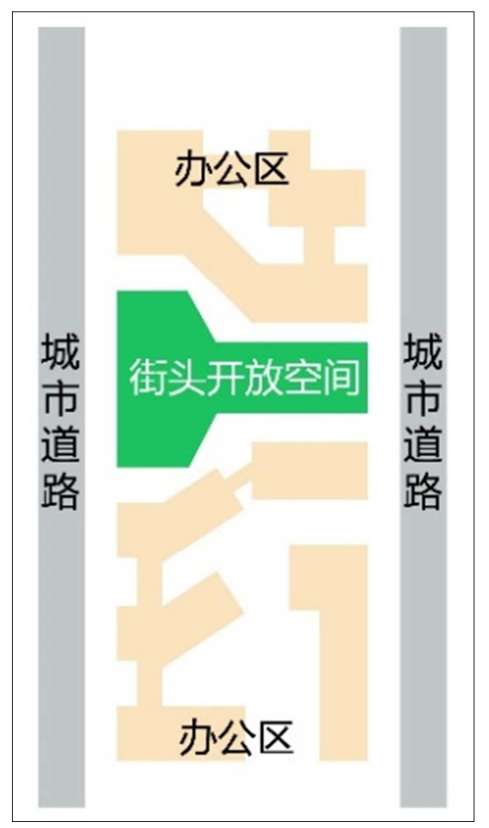

图11 模式四。 


\section{2. 从植物配置角度改善寒地景观}

\section{2. 1. 街头开放空间的树种选择与植物姿态}

植物配置是寒地城市街头开放空间设计极其重要的 一环, 要从美学角度、生态角度、树种本身的生长特性及 当地的气候条件进行综合考虑。具有当地地方特色及历史 文化的树种选择是区分地域的显著标志之一, 因此挖掘适 宜的寒地本土树种对于街头开放空间景观的营造十分必 要。常绿树是寒地运用造景的主要树种, 对于增加空气湿 度、改善局部空间小气候有良好的生态作用，但在配置设 计时应控制好常绿树与落叶树的比例关系, 尤其在冬季, 阴䨪环境下, 过多覆满尘土的常绿树种会造成空间的阴冷 之感。其次, 还应注意常绿树与落叶树的种植位置, 在冬 季盛行风向的上风向处应以常绿树为主, 而在东南方向上 适量配置落叶树, 这样不仅有利于冬季抵挡寒风, 最大程 度争取日照, 还有利于夏季遮阴通风。

除了考虑植物配置在寒地的防寒效果外, 还应重视 冬季植物景观的观赏价值, 常绿树伴随着冬季雪量的增 加, 呈现出寒地独有的树挂、雾淞等景观之美。对于落 叶树的冬态美则可以从树干及树枝的姿态美、色彩美等 方面挖掘, 从而为寒地冬季的街头开放空间营造友好的、 宜人的景观环境。

\subsection{2. 街头开放空间的植物层次与色彩}

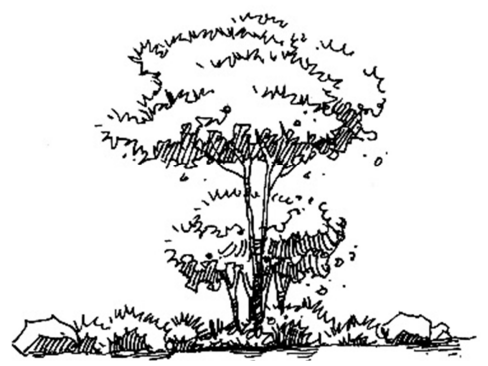

图12 植物配置的三级结构。

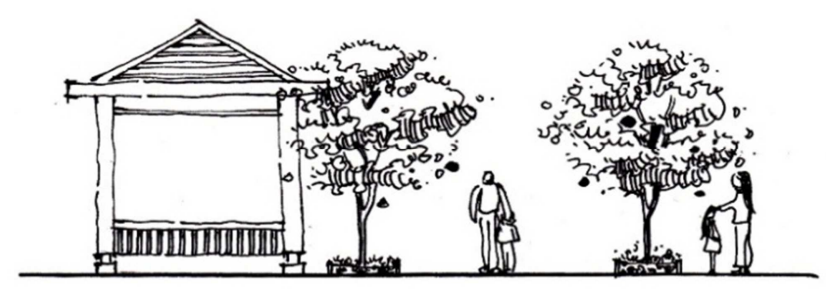

图13 植物配置的二级结构。

在城市街头开放空间景观设计中, 植物种植不仅讲究 “适地适树”原则, 还要讲究科学的配置方式, 如园林造景 中的孤植、对植、丛植、群植等, 注重构造景观的视觉空 间与层次。在街头开放空间私密、半私密空间处采用垂直 绿化的三级结构即乔木、灌木、草坪进行综合配置，从而 起到良好的遮阴、防寒、降噪的效果。在开放空间处可配 置高大乔木与草坪的二级结构, 这样有助于为活动人群提 供可视化空间, 如可有效保证家长对儿童的看管, 满足人 们对空间使用的安全性要求（如图12、图13）。
此外, 植物景观的色彩也是街头开放空间设计的关键 点之一, 不仅要考虑植物与植物之间的色彩配合, 还要考 虑植物与周围建筑色彩的相互协调。植物色彩越明亮, 体 积就越显膨胀, 令人感觉距离越近, 色彩明度越低, 体积 就越缩小, 产生后退感。因此空间狭小时, 为不让人感觉 局促, 可以配置明度稍低的植物, 过于空旷的空间, 可以 配置些色彩浓烈的植物, 形成视觉的焦点, 减弱空旷感。

\section{3. 从景观设施角度改善寒地景观}

\section{3. 1. 街头开放空间景观设施的选择}

街头开放空间的景观设施可以分为两种, 一种是常 规的景观设施, 满足广场各种活动正常进行的必备设施: 如座椅、路灯、果皮箱、电话亭等; 另一类是, 寒地城 市街头开放空间特有的景观设施：拥有气候防护作用的 亭、景观墙、健身器材、廊灯, 以及冬季特有的以冰、 雪为材料所制造的景观小品等。在冬季较寒冷的环境在 可以采用与广场周围建筑结合的加温的休息亭、玻璃棚 架等, 天气寒冷时开启, 或是采用设置在冬季盛行风向 上风向的具有文化内涵的防风景观墙, 在局部空间可营 造小气候及小景观, 为人们冬季进行室外活动提供空间 (如图14、图15)。

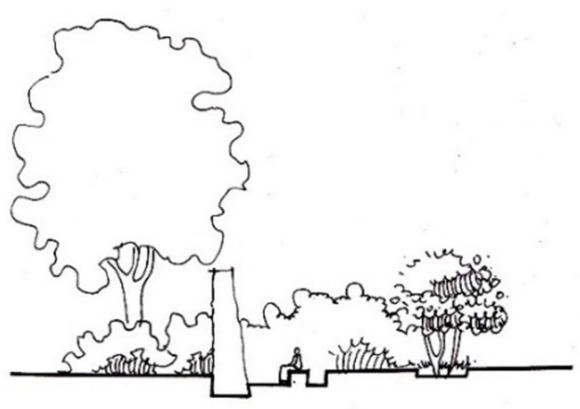

图14 有趣味性的防风景观墙。

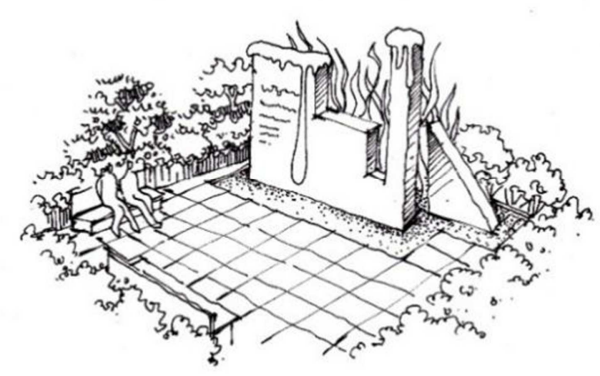

图15 有观赏性的文化景观墙。

\section{3. 2. 街头开放空间景观设施的材质与色彩}

在城市街头开放空间中景观设施的材质是最为本质 的一个要素, 它通过触觉带给人最直接的生理和心理感 受。景观设施的材料可分为自然和人工材料两大类, 自 然材料包括木材和石材，人工材料包括混凝土、金属材 料、玻璃、陶瓷、玻璃钢及塑料等合成材料。冬季的寒 地城市, 气温常低于零摄氏度, 因此在选择设施材料时 要充分考虑到各种材料在低温下的特性。加工容易、保 
温性能好、触感良好的木材与金属等其他材料相比，给 人以质朴温暖的印象, 符合寒冷气候下人们的生理和心 理需求, 如可作为园桌、园椅等使用, 但要做好防腐、 防水等措施以保证其使用寿命。而石材的防水防火、抗 腐蚀能力强、坚硬耐磨的特点是其作为景观设施基座的 最佳选择, 如雕塑、垃圾桶、园灯等, 不宜作为直接接 触人体的坐具的表面材料(如图16、图17)。

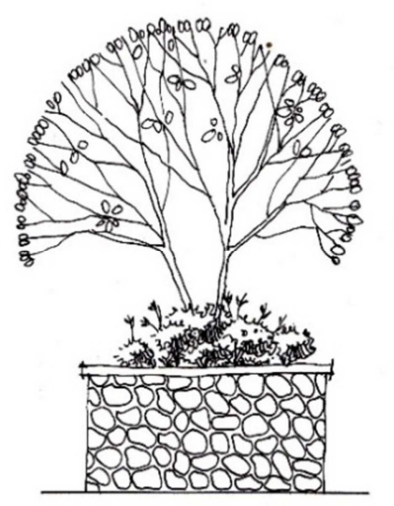

图16 冬季冰冷的石制树池。

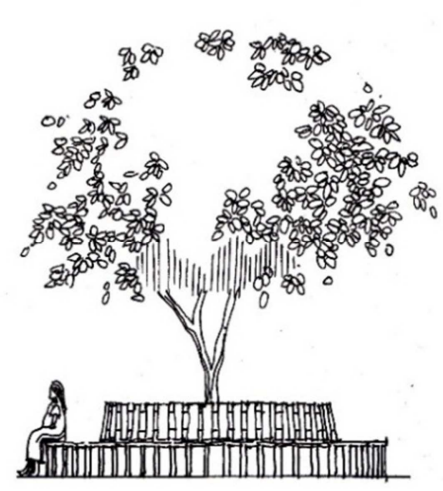

图17 冬季温和的木制树池。

在街头开放空间景观设计中, 将景观设施与植物、建 筑、水体等色彩相近的景观要素互相搭配，可以营造空间 的错落感和层次感。近似色与对比色在冬季景观设施设计 中均有应用, 近似色是同色系的颜色, 可以形成调和、统 一的效果, 用来营造比较舒缓的气氛。但对于寒地冬季景 观来说, 恰恰需要一种较为强烈的视觉冲击, 来形成富有 吸引力的景观效果才能突破冬季沉问的环境氛围, 因此在 寒地城市绿地冬季景观设计中, 景观设施的色彩应用应以 对比色为主, 尤其是饱和度较高而且色彩较艳丽的色彩更 能唤起人们在冬日的活力和热情。同时, 在载体相同的情 况下, 对比色的应用要格外注意, 那些饱和度较高, 与周 围环境及其他景观设施色彩对比极为强烈的色彩可以小 面积应用。

\section{5. 结论与展望}

城市街头开放空间是形形色色城市公共生活的兼容 并蓄的容器体系, 是城市中人工与自然元素交织融合的有
机系统。本文通过对寒地环境约束下城市街头开放空间规 划设计问题及对策的探究, 明确了科学和艺术的方法是解 决设计问题的关键。在某种意义上讲, 对城市街头开放空 间形态秩序、景观设计的梳理，能促进城市公共生活的发 生、提高城市生活质量、提升城市形象、彰显寒地地域环 境下独特的城市鬼米力。

\section{致谢}

本文为基金项目: 黑龙江省研究生教育教学成果奖培 育项目（CGPY-201431）经费资助。

\section{参考文献}

[1] (美) 克莱尔·库珀·马库斯等 (俞孔坚等译).人性场所城市开放空间设计导则 (第二版) [M]. 北京: 中国建筑工 业出版社，2001。

[2] (美) 凯文·林奇. 方益萍, 何晓军译. 城市意象 $[M]$. 北京: 华夏出版社, 2001。

[3] 林玉莲, 胡正凡. 环境心理学[M]北京中国建筑工业出版社, 2000:102。

[4] 王珂, 夏键, 杨新海. 城市广场设计 [M]. 南京: 东南大学出 版社, 1999。

[5] 陈建华. 珠江三角洲地区休憩广场环境及行为模式研究 [M]. 北京: 中国建筑工业出版社, 2011。

[6] 吴宦漳, 赵天宇. 寒地城市广场行为模式及影响因素研究 ——哈尔滨市建筑艺术广场为例 $[\mathrm{A}]$. 中国城市规划学会. 城市时代，协同规划—-2013中国城市规划年会论文集 (02城市设计与详细规划）[C]. 中国城市规划学会：2013:9。

[7] 徐苏宁. 创造符合寒地特征的城市公共空间——哈尔滨 为例 $[\mathrm{J}]$. 时代建筑, 2007,06:27-29。

[8] 冷红, 郭恩章, 袁青. 气候城市设计对策研究 [J]. 城市规划, 2003,09:49-54。

[9] 邵亮. 寒地城市生态公园规划设计研究[D]. 东北农业大学, 2013。

[10] 柯金金. 寒地城市口袋公园人性化设计研究 [D]. 东北林业大 学, 2011。

[11] 袁青, 冷红. 寒地城市广场设计对策 [J]. 规划师, 2004,(11):59-62。

[12] 陈强. 唐山地区冬季植物配景分析 [J]. 现代园艺, 2016,(06):62-63。

[13] 董带根. 城市街头绿地景观设计浅析 [J]. 中华民居（下旬 刊）,2014,(02):4。

[14] 新浪网。《松北呼兰利民开发区松花江避暑城将合一发 展》.http://hlj.sina.com.cn/news/b/2014-09-28/1338148708.ht $\mathrm{ml}$. 